\title{
ESTRATEGIAS DE UN ESPACIO DRAMÁTICO COMPLEJO Y EL DELIRIO PERSECUTORIO EN EL MARTIRIO DEL PASTOR
}

\author{
STRATEGIES OF THE COMPLEX DRAMATIC SPACE AND THE PERSECUTION \\ DELUSION IN EL MARTIRIO DEL PASTOR
}

Jorge Chen Sham*

\begin{abstract}
RESUMEN
En su propuesta de montaje de El martirio del pastor (1982), Samuel Rovinski propone una búsqueda de una relación directa y eficaz, desde el punto de vista dramático y teatral, entre los lectores/espectadores y la realidad mostrada en el texto. La disposición de la escena y el código escenográfico, así como la irrupción de los actores para romper la cuarta pared, tienden al acercamiento del público. Este efecto envolvente se vuelve eficaz para construir un fuerte vínculo con la realidad extra-dramática, pues los procedimientos de verificación y autentificación se logran por medio de las dos pantallas que historizan y dan impacto documental y ponen en escena el delirio persecutorio que convierte al protagonista de la obra en víctima expiatoria.
\end{abstract}

Palabras clave: Samuel Rovinski, El martirio del pastor, Monseñor Óscar Arnulfo Romero, teatro costarriense, víctima expiatoria, crónica-testimonio

\begin{abstract}
**
In the staging of his play El martirio del pastor (1982), Samuel Rovinski proposes a search for a direct and effective relationship, from a dramatic and theatrical standpoint, between readers / viewers and the reality shown in the text. The stagecraft and the use of theatrical codes, on one hand, and the role of actors in the breaking of the fourth wall, on the other hand, ease the identification of audiences. This serves to build a strong bond with extra-dramatic reality, where the verification and authentication procedures are achieved through these two devices that historicize while they chronicle the story and give life to persecutory delusions which make a scapegoat out of the protagonist.
\end{abstract}

Key Words: Samuel Rovinski, El martirio del pastor, Monsignor Oscar Arnulfo Romero, Costa Rican theater, the scapegoat, chronic-witness. 
Con El martirio del pastor (1982), Samuel Rovinski produce un texto dramático que relee el presente centroamericano de guerras civiles y de conflictos entre los regímenes de derecha y la toma de posición de izquierdas y de Iglesia en la América Central de los 70 y 80. La muerte del arzobispo salvadoreño Monseñor Óscar Arnulfo Romero, ocurrida el 24 de marzo de 1980, es tan reciente tanto en la memoria socio-cultural centroamericana como en la conciencia de las izquierdas comprometidas que obligó en aquel momento a una lectura testimonial de El martirio del pastor, así "el teatro sirve para dar voz a los oprimidos en la afirmación de sus derechos humanos" (Champagne, s. p.). De esta manera, leído en clave autentificadora de la realidad salvadoreña y bajo esa posibilidad de que los acontecimientos dramatizados por Rovinski nos acerquen a una versión de los intríngulis y pormemores del asesinato de arzobispo Romero, el texto dramático pasaría la prueba de verdad documental y de acercamiento imparcial a los hechos. La pregunta básica siempre es la misma: ¿cómo se construye la versión de los hechos?, lo cual nos conduce a una segunda pregunta, ¿cuál es su modo de representación? Leída en este contexto de producción, la historia del arzobispo Romero, quien se enfrenta a la propaganda y terror de un régimen de derecha a manos de Oligarcas y Terranientes, pone en escena la misma situación de atropello de las libertades y de censura en América Central de los años setenta y ochenta.

En ese sentido, Rovinski nos plantea en sus "Sugerencias para el montaje", que acompaña el texto dramático, tres necesidades desde la intentio autoris para lograr esa efectividad política que desea:

1) Un espacio escénico con diversas plataformas y un centro espectacular que "represente el interior de una iglesia" (Rovinski, 1987: 9). Se plantea un espacio centrípeto pero a partir de la fragmentación del escenario dramático.

2) Un sistema de audio-envolvente con "[a] ltavoces distribuidos en la gradería"
(Rovinski, 1987: 9), el cual permitirá el rompimiento de la cuarta pared para lograr la efectividad dramática.

3) La iglesia estará custodiada, como si fueran sus dos columnas, por "dos pantallas" que "proyectarán escenas de la represión en el país, filmadas por camarógrafos de televisión, y diapositivas con imágenes en primeros planos de personajes aludidos, recortes de periódicos, alegorías religiosas y otras que puedan complementar la acción" (Rovinski, 1987: 10).

4) Los procedimientos de anacronismo/ distanciamiento que podrían haberse logrado con la utilización de otros géneros discursivos (periodismo, televisión, radio) están aquí al servicio de la verosimilitud y de la autentificación de los acontecimientos representados.

Así las cosas, lo que en las propuestas brechtianas tienden hacia la participación activa /liberación del espectador y a un modo de acercamiento/interpretación del espacio teatral, que el punto de vista del texto dramático sugiere y apunta (Ubersfeld, 1982: 153), tienden a construir un fuerte vínculo con la realidad extra-dramática, pues, como indica, el texto de Rovinski, "[e] el espectador debe tener constantemente la sensación de descubrir una realidad despojada de los elementos superfluos que no afectan la evolución de los acontecimientos" (Rovinski 1987: 10); es decir, de relación directa y eficaz desde el punto de vista dramático y teatral. Entonces, la disposición de la escena y el código escenográfico (luces, audio, el montaje en plataformas, la irrupción de los actores desde las butacas como lo veremos a continuación), es decir, lo que en las "Sugerencias para el montaje" se denomina como una disposición "de la gradería en forma de anfiteatro" (Rovinski, 1987: 9), tienden al acercamiento del público (Ubersfeld, 1982: 165) y al efecto envolvente, el cual se vuelve eficaz para lograr, desde una agenda política, la transparencia de lo que se representa en escena. 


\section{El martirio del pastor y los procedimientos de verificación/ autentificación de la crónica- testimonio}

Es innegable, entonces, que Samuel Rovinski se inserta en esa discusión que, en los años ochenta, problematiza el testimonio como arma de denuncia en contra de los regímenes de derecha y reivindique las luchas populares; así fue leído su texto en tanto biografía dramatizada que exponía los últimos días de Monseñor Romero en su camino hacia la cruz. La verdad de los hechos se logra mediante la ejemplificación de un caso paradigmático y el procedimiento de la crónica periodística se vuelve primario para lograrlo. Dos acepciones tenemos de crónica, dependen de su relación con el referente y la interpretación de lo expuesto: "Se define la crónica como el escrito en que se refieren sucesos verídicos por orden del tiempo y en otra acepción, como artículo periodístico sobre temas de actualidad" (Cartín, 1986: 33). Los procedimientos de verificación y autentificación se logran así, por medio de las dos pantallas que historizan y dan impacto documental a lo que se expone en escena, en el sentido que le otorgan credibilidad. Veamos tres ejemplos claves en $E l$ martirio del pastor:

A) Primera Parte, en la Tercera sección, "Los lobos aúllan amenazantes contra el pastor", se produce el segundo enfrentamiento entre los oligarcas y Monseñor Romero. En escena, la oligarquía recrimina a Monseñor el haberse apartado de su posición neutral y de buscar la confrontación social; Romero confiesa su convencimiento de que la guerra está declarada entre la Iglesia y la oligarquía salvadoreña, dueña de los medios económicos del país. Romero y su colaborador, el padre Rafael, se sientan y mientras el primero lee unos papeles, la didascalia indica que la luz se desvanece gradualmente mientras se escucha la lectura de las palabras de Monseñor:
"En ningún momento, ni aún en las situaciones más dolorosas de sacerdotes asesinados y de fieles cristianos muertos o desaparecidos, la Iglesia ha llamdo al odio ni a ka venganza... El amor de Jesús hizo que se dirigiese a todos los hombres, pero de una manera distinta: a los hombres deshumanizados por el afán de lucro les mostró claramente, por amor, el camino para recobrar su perdida dignidad de hombres; con los pobres, deshumanizados por la marginación, se sentó, también por amor, a su mesa, para devolverles la esperanza."

\section{(oscurece $^{1}$ )}

(En la pantalla, una secuencia del pronunciamiento de las organizaciones populares en el auditorio de la Universidad, sacado de un reportaje televisado.)

\section{ALTOPARLANTES \\ (escenario a oscuras)}

Nuestra sociedad está en peligro. Los comunistas nos invaden y quieren destruir a la Patria y los valores cristianos de la familia. ¿A dónde esán las autoridades? ¿Cómo permiten que en los mismos predios de la Universidad se reúnan los fascinerosos a tramar la destrucción de la Patria? Pedimos al Gobierno mano fuerte, sin contemplaciones, contra los criminales comunistas y sus cómplices. Pedimos también a las autoridades de la Iglesia que termine el coqueteo de los jesuitas con los comunistas. Emplazamos aquí a Monseñor Romero para que le responda a nuestras preguntas. Ciudadano, la Patria está en peligro, no te dejes engañar por los comunistas manejados desde Cuba y la Unión Soviética... Este es un comunicado de la Asociación de Cámaras Patronales... (Rovinski, 1987: 79-80).

La cita es larga pero necesaria para observar cómo el enfrentamiento en los diálogos entre el Oligarca 1 y Monseñor se lleva a otro nivel escénico, el de los manifiestos y la propaganda política, que recubre todo el teatro, pues los altavoces, recordemos según las indicaciones del inicio del texto, se han emplazado alrededor del auditorio para no dejar a nadie indiferente. En ambos bandos se ejerce la palabra para 
persuadir y convencer, eso es cierto; pero el tono de las palabras de Monseñor Romero difiere de la confrontación y de la estrategia de erigir un enemigo y sembrar el miedo del "Comunicado". Lo que las pantallas reproducen tiene un efecto verosimilitante, pues se insiste en el carácter documental y de actualidad inmediata de lo que ha esgrimido Monseñor en relación con la concientización de las organizaciones populares. Sin embargo, también funciona como catalizador de la acción dramática, destaca que, en la oposición de fuerzas entre las organizaciones populares y la oligarquía, representada aquí por las "Cámaras patronales", la Iglesia se decanta por la verdad del evangelio y el amor; busca la no-confrontación, que será imposible de asumir en el contexto de El martirio del pastor.

B) Segunda Parte, en la Quinta sección, "Los lobos rompen el cerco", la oligarquía está más exasperada con la posición asumida por Romero y les reclama tanto al Gobierno, en la persona del ministro de defensa, y al Vaticano, en la figura del nuncio, su acción tímida en contra de quien insiste en denunciar internacionalmente al Gobierno salvadoreño; en ese momento el Oligarca 1 lee un fragmento de la carta dirigida a Carter:

(furioso, lee)

"La actual Junta de Gobierno y sobre todo las Fuerzas Armadas y los cuerpos de seguridad desgraciadamente no han demostrado su capacidad para resolver, en la práctica política y estructuralmente, los graves problemas nacionales. En general,sólo han recurrido a la violencia represiva produciendo un saldo de muertos y heridos mucho mayor que los regímenes militares recién pasados cuya sistemática voiolación de los derechos humanos fue denunciada por la misma Comisión Interamericana de Derechos Humanos..." No continúo leyendo porque es insoportable. ¡Qué tipo más arrogante...! [...]

\section{MINISTRO DE DEFENSA}

Les advierto: no hagan nada que pueda perjudicar al gobierno...

\section{OLIGARCA 1}

(despectivo)

No se preocupe, general. Nosotros haremos el trabajo sucio.

\section{(oscurecimiento)}

(Por los altoparlantes el estampido de una bomba, seguido del crepitar de llamas. En la pantalla, las ruinas aún humeantes de la radioemisora católica Y.S.A.X.)

La voz del locutor:

("Sujetos desconocidos volaron hoy la radioemisora católica Y.S.A.X. con una carga de dinamita, luego de amordazar al guardian nocturno. La policía se encuentra investigando este reprobable acto de vandalismo. Ninguna organización de izquierda o de derecha se ha atribuido el atentado.")

(En la pantalla: “23 de marzo de 1980”).

$$
\text { (Rovinski, 1987: 144-145) }
$$

Observemos de nuevo el encadenamiento complejo de diferentes tipos de discurso: la carta dirigida al presidente Carter en la que Romero abiertamente denuncia el papel del Gobierno y su campaña de exacciones en contra de los derechos humanos, contrasta con las breves palabras de reclamo de la oligarquía, quien jura intervenir de facto. Lo que los altoparlantes reproducen luego se atestigua por medio de la foto del incendio y de la noticia radiofónica, a saber, del atentado terrorista a un medio de comunicación. Al escuchar primero los sonidos de la bomba y del incendio, para pasar luego a la imagen fotográfica de los despojos de las llamas, se crea una zozobra y unas expectativas que la noticia radiofónica colma. La fecha que indica la pantalla ubica históricamente el suceso y dimensiona, desde el punto de vista de la causalidad diegética, la responsabilidad de la oligarquía en la llamada "guerra sucia". El texto subraya un procedimiento de verificación documental, para que el testimonio sea aún más incisivo y pase a activar emociones y frustraciones en el lector/espectador. 
C) Segunda Parte. En Sexta sección, titulada "El holocausto", las amenazas de muerte se repiten y se producen insistiendo, en la acción dramática, en la crónica de muerte anunciada, tal y como se señala al inicio de esta sección. El complot se organiza y se pone como solución definitiva de que, al compromiso de base y a las denuncias de Monseñor Romero, los paramilitares actuarán:

\section{PISTOLERO 2}

No fallo nunca, Mayor...

\section{EX-MAYOR}

Más te vale, y no te olvides de las instrucciones...

\section{PISTOLERO 2}

No, qué me voy a olvidar. Entrego el arma aquí al compadre y me voy en el otro auto al aeropuerto...

\section{EX-MAYOR}

Bueno andando... Y ya saben: exactamente al final del sermón, cuando se ponga a hacer las mariconadas de la Eucarístía...

(los pistoleros se ríen y salen. Oscurecimiento).

(En la pantalla: "24 de marzo de 1980. Son las 6: 25 de la tarde". El ruido de un auto que frena cerca de la capilla. Monseñor está terminando la homilía frente a un grupo de gente, entre los que destacan las monjas y algunos sacerdotes. Un camarógrafo filma la escena).

(Rovinski, 1987: 151-152)

El procedimiento de verificación/ autentificación que cumple aquí la "pantalla" llama poderosamente la atención; no solo la fecha es importante en tanto ubicación temporal del acontecimiento, sino el procedimiento de mise en abyme, que se despliega ante nuestros ojos de lectores/espectadores de encuadre/enclave, hace que la pantalla muestre a un "camarógrafo" filmando la escena de la muerte de Romero; se trata de un efecto especular que problematiza no solo los límites entre la realidad y la ficción escénica, sino articula esa ilusión performativa propia de la representación en vivo: la filmación de la escena de asesinato, su actualización por medio de la pantalla, la asistencia al espectáculo teatral que hace performance de lo anterior. La representación está al servicio del testimonio y de la crónica periodística en el que, como en los media, la noticia se produce en vivo y el lector/ espectador puede acceder a ella sin problemas. La actualidad de la crónica se asegura por medio de estos procedimientos de testimonio documental, de manera que la intencionalidad política es transparente en esta adecuación entre la acción dramática y los procedimientos para atestiguar la verdad de lo que se representa.

\section{El sentido de la crónica-testimonio y el "delirio de persecución"}

En el sentido tradicional, Monseñor Romero es mártir de una causa. No se nos olvide que "mártir" es aquel da testimonio de su fe y, por eso, ha muerto por sus creencias y convicciones; no quiero continuar con este aspecto que ya ha sido abordado por Mario Rojas y, principalmente por Kristin Shoaf en su relación con la teología de la liberación, porque, para este último, esta redinaminazión de la utopía socialista en contra de la opresión y la injusticia, reconoce a los pobres y se posiciona en una catequesis de los oprimidos (s. p.). Más interesante sería relacionar la noción del testimonio con los mecanismos de control de las sociedades occidentales en la figura de un pastor del rebaño del Señor, quien se enfrenta a la propaganda y a la destrucción política de un régimen que ejerce su censura y atropella las libertades. El martirio del pastor estudia cómo se entretejen los hilos de la manipulación del poder y se justifica la violencia de Estado; para ello Monseñor Romero debe ser presentado como una víctima sacrificial, perseguida $\mathrm{y}$ eliminada por razones de bien público, orden e intereses nacionales. En este sentido, Monseñor 
Romero es presentado, ya lo vimos, como nocivo y perjudicial para la nación; por eso esos "lobos" con piel de cordero que lo persiguen. René Girard, quien ha estudiado esta representación de la violencia ritual de las sociedades en la figura del chivo expiatorio o la víctima sacrificial, nos señala que, en tiempos de crisis, de desórdenes traumáticos, el apetito persecutorio recrudece $\mathrm{y}$, centrándose en la figura de la víctima, subraya la perspectiva de los perseguidores:

\footnotetext{
Cette perspective est forcément trompeuse en ceci que les persécuteurs sont convaincus du bien-fondé de leur violence: ils se prennent pour des justiciers, il leur faut donc des victimes coupables, mais cette perspective est partiellement véridique car la certitude d'avoir raison encourage ces mêmes persécuteurs à ne rien dissimuler de leur massacres. (Girad, 1982: 13).
}

Girad nos habla de un delirio de persecución, eso es lo que encontramos en El martirio del pastor, cuando se justifiquen las razones que posee el poder político para eliminar a la persona de Monseñor Romero. Es lo que se va configurando a partir de la Tercera Sección "Los lobos aúllan amenazantes contra el pastor". El epígrafe seleccionado por Rovinski nos da la clave; se trata del último versículo del breve Salmo 120: "Soy todo paz; mas, cuando hablo, ellos mueven la guerra" (La Santa Biblia, 1974: 735). Esta dicotomía paz/guerra no puede entenderse si no tomamos en cuenta el resto del Salmo, cuyo subítulo es "Contra las lenguas inicuas":

Hacia Yavé, cuando estaba angustiado, clamé y él me respondió.

¡Oh, Yavé, salva mi alma

de los labios mentirosos,

de la pérfida lengua!

¿Qué te va a dar, qué te va a añadir,

oh lengua pérfida?

Flechas afiladas de guerrero

y brasas de retama.

¡Ay de mí, que vivo en Mesec,

habito en la tienda de Cedar!

Harto ha vivido mi alma

con los que odian la paz.

(La Santa Biblia, 1974: 735).
Aunque el 120 es un salmo que se clasifica como gradual, marcado por las etapas de la peregrinación hacia Jerusalén, "[e]1 salmista ve en ello una respuesta de Dios a su angustia" (Mannati 1979: 46) y se presenta como un perseguido por las insidias humanas, "la pérfida lengua" que lanza críticas, censura y miente hasta figurarse cercado ante el guerrero y hastiado de este clima virulento de guerra. Además, no es inocente la confluencia que hace el salmista entre la "lengua pérfida" y la "flecha afilada"; las mentiras y las armas funcionan de la misma manera, mientras se pide la pronta intervención divina, contra las palabras mentirosas y la insidia humana, que solamente censuran para dañar la imagen del otro, destruyendo figuradamente hablando el cuerpo también. Por eso, no es casual que el salmista se presente como desamparado y sufriente, al tiempo que su exclamación angustiosa da cuenta de su situación del que ora, maltrecho y abatido porque lo acorrolan y asfixian sus enemigos (García Trapiello, 1997: 111). Como veremos esto no es casual en la sistemática del texto, porque en un sentido figurado, acorrar a la víctima es restringirle el espacio en el que puede moverse hasta eliminarla. De esta manera, en el texto dramático asistimos a esta sistemática del terror en el que las palabras y los hechos de lo que se ensañan sobre Monseñor Romero, lo configuran como blanco de su discurso y justifican las razones por las que debe eliminarse (por razones de Estado, de salvación de la "democracia", de la "estabilidad nacional"), lo cual termina con el magnicidio. Veamos otro ejemplo en donde se configura claramente esta figuración del "blanco" de todos los ataques y críticas del poder hegemónico. En el escenario de plataformas múltiples, aparece el despacho presidencial en el que el mandatario recibe a los representantes de la oligarquía $y$, exasperados estos últimos, demandan la pronta intervención del Estado:

\section{PRESIDENTE}

Como usted dice..., si son cómplices. Pues bien, si son cómplices los trataremos con la 
misma medida. Por lo que respecta a Monseñor, prefiero ser prudente y esperar...

\section{OLIGARCA 2} Aguilares?

¿Esperar...? ¿No oyó usted la homilía en

\section{OLIGARCA 1}

¿Y las denuncias por la Radio Católica...?

\section{PRESIDENTE}

Sí es cierto, pero sigo creyendo que no es tan grave. Ya se le pasará...

\section{OLIGARCA 1}

¿Y esa actitud tan altanera de no asistir a su toma de posesión...? Hasta el Nuncio y los otros obispos lo criticaron... (Rovinski, 1987: 68).

La razón de Estado y las lenguas viperinas y facciosas hacen que el enemigo tome cuerpo en la figura de Romero. De manera que la oligarquía increpa al Gobierno en lo que llamemos el proceso de ensañamiento y de persecución, porque se trata de una estrategia cuya finalidad es "dañar la imagen positiva del contrario" (Bolívar, 2005: 146), ya que cumple con la producción de diferentes efectos que tienden a la amenaza de la imagen de Monseñor Romero:

1) Ridiculizar. El objetivo es "convertir al oponente en objeto de burla, hacer que los demás se rían de su persona, acciones o decisiones" (Bolívar, 2005: 148).

2) Humillar. El objetivo es "degradar al oponente en su estima personal, profesional” (Bolívar, 2005: 148).

3) Descalificar. El objetivo es "resaltar los rasgos negativos de los oponentes en cuanto a: capacidad intelectual [...], credibilidad, coherencia, responsabilidad, cualidades personales" (Bolívar, 2005: 148).

La configuración de la víctima expiatoria es paralela a la rivalidad encarnecida que se erige entre los dos bandos en conflicto.
El establecimiento del brazo armado de la oligarquía, lo que se denomina "El escuadrón de la Muerte", atestigua de este agravamiento de la situación, cuando abiertamente se postula y se justifica la eliminación del adversario, de aquellos que son contrarios a "usted" ; así lo plantea el Mayor cuando se dirige al Presidente y utiliza la imagen calórica para excluir a los que no son de su bando y no siguen sus ideas políticas y todo ello para plantear el convencimiento y el compromiso que ahora adquieren a favor del orden y de la estabilidad:

\section{MAYOR}

Los tibios también, general. No hay que discriminar a los opositores. Los tibios se vuelven calientes y entonces es más difícil eliminarlos. Cuando se elimina a un par de tibios, el resto se enfría. Les da canillera.

(ríe)...

\section{PRESIDENTE}

Mayor, usted me da miedo...

MAYOR

(riéndose)

¿A usted, miedo...?

(ríe)

Señor Presidente, eso es un piropo... Usted es el que manda aquí... ¿Acaso no sabemos lo que se propone con la ley de seguridad nacional? Usted es el escritor y nosotros los actores. Lo que yo haga usted lo ha pensado así.

\section{PRESIDENTE}

¡Cuidado, enróllese esa lengua de culebra...! Si alguien me acusa de sus desapariciones, lo quemo a usted. Manténgase a la sombra. Será bueno para su salud... (Rovinski, 1987: 96-97).

La eliminación y el exterminio se vuelve política de Estado aquí. Ante tal sed de muerte, la comparación del Mayor, que hace el Presidente, con una culebra no es casual, porque la maldad se expresa en esa cara iluminada que se ríe con sadismo y se imagina las 
exacciones que cometerá, lo que el Presidente resume con el término de "desapariciones". Sin embargo, toda la estrategia de la derecha y de los grupos paramilitares de los años 80 se encuentra codificada en esta eliminación de los que el Mayor denomina como los“opositores” al régimen, al tiempo que se despliega la "guerra sucia" en la que el Gobierno pretende que su brazo armado esté o se mantenga, como indica el Presidente, "a la sombra". Desde este momento es claro que la lucha entre los dos bandos enfrentados sera desigual y que, entre bastidores y en las oficinas y cuarteles del Poder, se va armando esa campaña orquestada por el Gobierno y la oligarquía en contra de las organizaciones populares y en contra de quien los ha traicionado, Monseñor Romero. En el silencio y en la impunidad, reunidos en asociación, militares, oligarcas y gobiernos se juntan para tramar algo, para conspirar. Recordemos que "conspirar" viene en latín de la raíz spirare, "soplar, respirar"; etimológicamente conspirare significa "respirar juntos" y de ahí su sentido figurado de "estar de acuerdo" (Corominas 1992: 748). El verbo conspirar denota la oposición y el enfrentamiento de quien se alía a otro $y$, en este caso, tramar su eliminación política $y$, en este sentido figurado, no permitirle respirar haciéndola sentirse acosada y cercada, tal y como explicaba el "Salmo 120".

Según destaca René Girard, la figura de víctima expiatoria es necesaria para comprender cómo las sociedades pueden encauzar la violencia constitutiva de sus relaciones y la crisis mimética originada en momentos en que el peligro desemboca en confusión y en destrucción, de manera que para neutralizar el caos y la inestabilidad, deba erigirse una figura que la encarne (1978: 35-36). Así, el último versículo del "Salmo 120", que sirve de epígrafe al texto ("Soy todo paz; mas, cuando hablo, ellos mueven la guerra"), aunque responde a la propuesta de paz evangélica neotestamentaria, tiene más pertinencia en este contexto de la persecución y de la víctima expiatoria. El salmista es, en este "Salmo 120", un perseguido y un acusado inocente (Mannati 1979: 14) que expone los dos procedimientos que sus enemigos han tramado para acabar con él: la "lengua pérfida" y las "flechas afiladas de guerrero/ y brasas de retama" (v. 3-4); es decir, las palabras y los hechos consumados como el asesinato a sangre fría del magnicidio. Así, esta crisis se resuelve de manera ficticia con el encauzamiento de la hostilidad grupal hacia un solo individuo, capaz de resumir, en forma simbólica, los antagonismos que generan la crisis, tal y como se expone en la Segunda Parte, sección 6, "El holocausto", con esta remisión a una experiencia colectiva de exterminio. Las equivalencias entre la eucaristía y el sacrificio no se hacen esperar:

\section{MONSEÑOR}

"Esta San Misa, pues, esta Eucaristía, es precisamente un acto de fe. Con fe cristiana parece que en ese momento la voz de diatriba se convierte en el cuerpo del Señor que se ofreció por la redención del mundo y que, en ese cáliz, el vino se transforma en la sangre que fue precio de la salvación. Que este cuerpo inmolado y esta sangre sacrificada por los hombres, nos alimente también para dar nuestro cuerpo y nuestra sangre al sufrimiento y al dolor, como Cristo; no para sí, sino para dar conceptos de justicia y de paz a nuestro pueblo. Unámonos pues, íntimamente en fe y esperanza a este momento de oración."

(se encamina hacia el altar para los preparativos de la Eucaristía.)

(Cuando toma la copa en sus manos, suena un disparo. Lo han herido mortalmente en el corazón. Se escucha el chirrido de las llantas del auto que huye. Las monjas corren hacia Monseñor. Tratan de levantarlo. Al darse cuenta de que está agonizando, lanzan gemidos desgarradores. La gente corre, unos hacia la puerta de la capilla y otros a auxiliar a Monseñor. La misma escena aparece en las pantallas, como fue captada por el camarógrafo. El escenario se oscurece. Sólo un proyector se concentra en las dos monjas que tienen en sus regazos al moribundo, como reproducción de 
una imagen piadosa). En la pantalla, el siguiente letrero:

"La palabra queda. Y ésta es el gran consuelo del que predica. Mi voz desaparecerá, pero mi palabra, que es Cristo, quedará en los corazones que la hayan querido acoger.” (17.12.1978). (Rovinski, 1987: 153).

En primer lugar, Monseñor lee en voz alta la homilía que está escribiendo para este ocasión final; en ella, la idea de la eucaristía se nutre de las palabras de la Última Cena narrada por los evangelios y que son las palabras propias del rito de la transustanciación en la eucaristía; $\sin$ embargo, observemos dos elementos que llaman poderosamente la atención:

a) El hecho de que Monseñor Romero aluda a sí mismo en estos términos: "la voz de diatriba se convierte en el cuerpo del Señor", patentiza la relación que establece entre la situación de ensañamiento que sufre en carne propia con la persecución de Jesús; con "la voz de diatriba" se refiere a las palabras de odio y de censura con las que han justificado su muerte y le han puesto precio a su cabeza.

b) Pasa en segundo lugar al sacrificio colectivo y grupal cuando enfatiza que el cuerpo y la sangre de Cristo se transforman en fruto dimensionado socialmente, "nos alimente también para dar nuestro cuerpo y nuestra sangre al sufrimiento y al dolor, como Cristo; no para sí, sino para dar conceptos de justicia y de paz a nuestro pueblo"; es decir, el sacrificio de Jesucristo es un testimonio que debe alentar y estimular al cristiano en su proyecto de salvación y de redención humanos.

La homilía, leida por Monseñor Romero, anticipa así el evento que se producirá inmediatamente, narrado así por las didascalias para explicar lo que en escena es solamente la confirmación del mensaje catequístico del sermón. Su efecto es aplastante y no deja indiferente al lector/espectador, quien debe, en esta crónica de una muerte anunciada y ante los hechos consumados, preguntarse por su posición y su respuesta. El procedimiento de las "pantallas" se vuelve otra vez apelativo y afectivo, busca la transparencia documental y testimonial, cuando se indica que "[l]a misma escena aparece en las pantallas, como fue captada por el camarógrafo", porque se trata no solamente de narrar en directo, sino también de que, a través de la pantalla, su lente funcione como los ojos del lector/espectador insertados en tal simulacrum de la realidad.

Ahora bien, las relaciones de la eucaristía del rito católico con el sacrificio personal de Monseñor Romero permite esbozar, más allá de la cuestión biográfica a causa de las circunstancias de su muerte, la pertinencia de una sustitución del antagonista en una víctima expiatoria que muera en sacrificio colectivo. Lo interesante es que esta rivalidad genere una lucha encarnizada por el poder y una fascinación por el rival que es Monseñor Romero, tal y como se ha analizado en este trabajo. En efecto, la acción dramática de El martirio del pastor gira en torno a un proceso de persecución (Girard 1982: 21) y esto queda claro desde este momento en que los militares busquen eliminarlo y lo ejecuten al final de la acción dramática. ¿Qué logra con esto Samuel Rovinski? Precisamente, en Anatomía del realismo (1965), releyendo las estrategias brechtianas del teatro con alcances políticos, el dramaturgo español Alfonso Sastre formulaba una estética con función social y, en un momento en que se avecinaban esas grandes rupturas ideológicas cuyo hito capital es el 68 , hace de la revolución el objetivo propio de la escritura; indica Sastre: "Precisamente, la principal misión del arte en el mundo injusto en que vivimos consiste en transformarlo. El estímulo de esta transformación, en el orden social, corresponde a un arte que, desde ahora, podríamos llamar de 'urgencia' [...]. Sólo un arte de gran calidad estética es capaz de transformar el mundo" (1965: 17).

Creo que tales palabras tienen su eco en este texto de Samuel Rovinski, en donde la escritura dramática supondrá que las transformaciones deben darse no sólo en el proceso de escritura, sino también en el de su representación; debe suscitar una experiencia liberalizadora con una toma de conciencia, pues su ethos, en su sentido aristotélico, intenta 
provocar estados de ánimo que apuntan a una acción purificadora. La importancia de esta toma de posición ideológica conduce, a su vez, a una posible acción política y revolucionaria, lo cual sería básico para comprender los alcances de una función social del teatro. Al denunciar el ensañamiento y el delirio de persecución en contra de Monseñor Romero, su martirio cobra toda la significación que poseía para la iglesia cristiana primitiva la prueba de fe, con lo cual Rovinski reactualiza y hace memoria de la resistencia y lucha del carismático obispo. Su efectividad socio-política subvierte el proyecto devastador y degradador de la derecha militar centroamericana. Se trata de una forma teatral, cuya vocación es proponer al público un tema actual y comprometido. Su respuesta desemboca en una acción desmitificadora e irreverente contra el statu quo; mientras el lector/espectador "es siempre invitado, y hasta presionado, a tomar partido, a sumarse al proceso revolucionario codificado en el drama" (Ruiz Ramón 1975: 413), a lo cual obliga una vez más las palabras de Monseñor Romero que la pantalla reproducen para observar la impronta de su mensaje y la realidad escatológica de sus planteamientos: "Mi voz desaparecerá, pero mi palabra, que es Cristo, quedará en los corazones que la hayan querido acoger" (Rovinski, 1987: 153).

\section{Bibliografía}

Bolívar, Adriana. 2005. "La descortesía en la dinámica social y política", Actas del II Coloquio Internacional del Pograma EDICE "Actos de habla y cortesía en distintas variedades del español: Perspectivas teóricas y metodológicas", Jorge Murillo Medrano (Ed.), Estocolmo/ San José: Programa EDICE/ Instituto de investigaciones Lingüísticas.

Cartín de Guier, Estrellita. 1986. "Formas de lo trágico en Crónica de una muerte anunciada", Káñina, Revista de Artes y Letras de la Universidad de Costa Rica 10.1: 33-38.
Champagne, Carole A. "El mensaje inmediato de una tragedia colectiva". Istmo 18. http://istmo.denison.edu/n18/articulos/ champagne.html. Consultado el 24 de abril del 2013.

Corominas, Joan y José A. Pascual. 1992. Diccionario crítico etimológico castellano e hispánico. Madrid: Editorial Gredos, volumen II, $2^{\text {a }}$. reimpresión.

García Trapiello, Jesús. 1997. Introducción al estudio de los Salmos. Salamanca: Editorial San Esteban.

Girard, René. 1978. Des choses cachées depuis de la fondation du monde. París: Bernard Grasset.

1982. Le bouc émissaire. París: Editions Grasset \& Fasquelle.

Mannati, Marina. 1979. Orar con los salmos. Estella: Editorial Verbo Divino, $2^{\mathrm{a}}$. edición. Rojas, Mario A.

Rojas, Mario A. 1989. "El martirio del pastor de Samuel Rovinski: la dramatización de lo inmediato". Reflexiones sobre el teatro latinoamericano del siglo veinte. Miguel Angel Giella y Peter Rosler (Eds.). Buenos Aires: Editorial Galerna/Lemecke Verlag: 153-160.

1989. "El misterio del Pastor y su referente. Alba de América 7.12-13: 117129.

Rovinski, Samuel. 1987. El martirio del pastor. San José: EDUCA, $2^{\mathrm{a}}$. edición.

Ruiz Ramón, Francisco. 1975. Historia del teatro español: siglo $X X$. Madrid: Ediciones Cátedra, 2a. edición.

Santa Biblia, La. 1974. Madrid: Ediciones Paulinas. 
Sastre, Alfonso. 1965. Anatomía del realismo, Barcelona: Seix Barral.

Shoaf, Kristin E. "El martirio del pastor dentro del contexto del pensamiento de liberación: el papel de la Iglesia como opción preferencial de los pobres". http:// www.ensayistas.org/critica/liberacion/ TL/literatura/shoaf.htm. Consultado el 24 de abril del 2013.

Ubersfeld, Anne. 1982. Lire le Théâtre. París: Éditions Sociale, $4^{\mathrm{a}}$. edición.

\section{(@) $\odot \Theta$}

Este obra está bajo una licencia de Creative Commons Reconocimiento-NoComercial-SinObraDerivada 4.0 Internacional. 
